\title{
Pharmacological aspects \& medicinal uses of Trigonella foenum-graecum: A Current Review
}

\author{
Review Article
}

\section{Veer Inder Singh ${ }^{*}$, Rahul Kumar Sharma², Yogesh Kumar³, Sadique Saqulain ${ }^{4}$}

\author{
1,3,4 Students, 2. Assistant Professor, Department of Pharmacology, \\ Amar Shaheed Baba Ajit Singh Jujhar Singh Memorial College of Pharmacy, Bela, Ropar, Punjab, India.
}

\begin{abstract}
Globally a large number of people are affected by acute and chronic diseases resulting in high morbidity and mortality rate. A huge amount of pharmaceutical drugs are being manufactured on a daily basis to combat these diseases. But due to their high cost and deleterious effects, it becomes critically important to state emphasis on finding an alternative way to manage these long term conditions. Medicinal herbs could provide a good source of dietary supplement combined with existing therapies. Many scientific studies have demonstrated that medicinal plants and herbs have the potential for the treatment of many serious infections and many disorders. Out of these herbs, Fenugreek is recognized as an oldest herb with great medicinal potential. Fenugreek harbors many essential macronutrients and micronutrients along with trace elements. Numerous chemical constituents present in fenugreek highlights a variety of pharmacological activity such as anti-glycemic activity, anti-oxidant capacity, antiinflammatory effects, hypocholesterolemic activity and many more. This article explores the diverse active compounds and potential pharmacological applications of Trigonella foenum-graecum also known as fenugreek. It also focuses on the medicinal significance and health impact of taking fenugreek in our day to day nutrition.
\end{abstract}

Key Words: Fenugreek, Trigonella foenum-graecum, Pharmacological activity, Phytoconstituents, Medicinal uses.

\section{Introduction}

India is a land full of diverse flora and fauna collectively referred to as Biota. India has a huge diversity of flora owing to its vast range of topology, climatic conditions as well as habitat. Flora has been regarded as a source of medicine since ages. Around 8,000 species in India have medicinal value. Out of these, Fenugreek is of great importance. Fenugreek is an annual aromatic plant grown throughout the Indian subcontinent (1) (2). The seeds and leaves of Fenugreek has anti-oxidant properties. Fenugreek is native to southern Europe and the Mediterranean region and India is regarded as largest exporter of Fenugreek throughout the world. In India, Rajasthan produces around $80 \%$ fenugreek of the country. Fenugreek is also globally known to be cultivated in specific parts of North Africa, Pakistan, Iran, Afghanistan, Russia, Australia, the USA, Argentina, Canada, Spain, Turkey, Nepal, Morocco and Lebanon (3) (4). It has been grown for centuries across the Indian subcontinent. The plant has its traditional roots in Ayurvedic medicines. The

* Corresponding Author:

Veer Inder Singh

Students, Department of Pharmacology,

Amar Shaheed Baba Ajit Singh Jujhar Singh

Memorial College of Pharmacy, Bela, Ropar,

Punjab, India.

Email Id: veerindersinghcheema@gmail.com
Binomial name of Fenugreek is Trigonella foenumgraecum belongining to family Fabaceae and subfamily Papilionaceae. The genus Trigonella is derived from Greek word meaning 'three angled' and the Latin word foenum-graecum meaning 'Greek hay'. Taxonomical classification is presented in table-1.

Traditionally, Fenugreek seeds have diverse uses such as antibacterial, anti-inflammatory, galactogauge, rejuvenating effects (5). Fenugreek is traditionally used for diabetes, painful menstruation, polycystic ovary syndrome and obesity. Various parts of fenugreek such as stem, leaves and seeds contain active constituents that are of great medicinal importance. Fenugreek seeds are aromatic seeds used as seasoning especially in curry. Many modern researches have established the role of fenugreek seeds and leaves in the treatment of several diseases comprising reduction of blood cholesterol and sugar levels in both clincal and non-clinical trials (6). In India, Fenugreek is popularly known as Methi. Many species of Fenugreek like $T$. balansae, T. carniculata, T. spicata, T. occulta, T. polycerata, T. calliceras, etc are all of great importance and cultivated globally $(7,8)$.

As Thomas Edison quoted "The doctor of the future will no longer treat the human frame with drugs, but rather will cure and prevent disease with nutrition"; Fenugreek has been used worldwide as a part of our day to day life with respect to healthy nutrition. 
Veer Inder Singh et.al., Pharmacological aspects \& medicinal uses of Trigonella foenum-graecum: A Current Review

Table 1: Taxonomic hierarchy of Fenugreek

Kingdom

Division

Class

Order

Family

Sub-family

Genus

Species

Plantae

Eudicots

Rosids

Fabales

Fabaceae

Papilionaceae

Trigonella

T. foenum-graecum

\section{Relevance of Phytochemicals present in Fenugreek}

Fenugreek is a major source of diverse active chemical constituents such as Flavonoids, Alkaloids $(0.36 \%)$, Saponins along with steroidal saponins $(0.1-$ $2.2 \%)$, Unsaturated fatty acids (6-10\%), fiber $(20 \%$ insoluble fiber \& $30 \%$ soluble fiber) (9), amino acids, vitamins (A, B1, C), mucilage (28\%), lipids, proteins
(22-25\%), and minerals (10). It also contains carbohydrates (45-60\%), calcium and iron. On hydrolysis, glycosides content yields steroidal sapogenins like diosgenin, neotigogenin, tigogenin, and yamogenin. Due to the presence of iron content, Fenugreek is considered good for iron-deficient patients (11). The seeds and leaves of Fenugreek also has an established role in reducing the cholesterol and blood glucose levels. Fenugreek seeds contain large amount of polyphenols, as suggested by many studies (12), which are naturally occurring phytoconstituents in plant kingdom that possess strong anti-oxidant properties. Also fenugreek seeds polyphenols prevented oxidative hydrolysis and lipid peroxidation caused by $\mathrm{H} 2 \mathrm{O} 2$ in vitro in human erthrocytes (13). The major phytoconstituents of fenugreek are presented in table-2.

Table 2: Phytochemical present in fenugreek

\begin{tabular}{|c|c|}
\hline Phytochemicals & Chemical constituents \\
\hline Alkaloids & Trigonelline, Choline, Gentianine, Carpaine, Trimethylamine, Neurin \\
\hline Saponins & $\begin{array}{l}\text { Graecunins, fenugrin B, fenugreekine (14), Yamogenin, diosgenin, sarsasapogenin, } \\
\text { neotigogenin, protodioscin }\end{array}$ \\
\hline Flavonoids & Quercetin, rutin, vitexin, isovitexin \\
\hline Amino acids & Isoleucine, 4-Hydroxyisoleucine, aspartic acid, leucine, arginine, proline, glutamic acid, lysine \\
\hline Fibres & Neutral detergent fiber, gum \\
\hline Lipids & Monoacylglycerols, diacylglycerols, triacylglycerols, free fatty acids \\
\hline Coumarins & Scopoletin, cinnamic acid (15) \\
\hline Others & Vitamin A, folic acid, minerals, mucilage, nicotonic acid, proteins, lenoleic acid \\
\hline
\end{tabular}

Fenugreek contains different proportion of active constituents in parts such as leaves and seeds. The leaves contain a variety of compounds including seven saponins (graecunins). Leaves also contain $86.1 \%$ moisture, fats, proteins and carbohydrates along with minerals and vitamins such as zinc, calcium, riboflavin, carotene, niacin, iron, phosphorous, vitamin $\mathrm{C}$, etc (16). The fresh leaves of fenugreek contain ascorbic acid and b-caroten in definite proportions (17). The seeds of fenugreek contain compounds like alkaloids (trigonelline, gentianine) flavonoids, saponins (diosgenin), proteins and even small amount of fixed oils and volatile oils (18). Polyphenolic compounds constituted major active components of the fenugreek seeds. Endosperm part contains the highest content of saponin and protein. Diverse active constituents along with various pharmacological activities of fenugreek are highlighted in the table-3.

\begin{tabular}{l|l|}
\hline Active constituents & Pharmacological activity \\
\hline Trigonelline & Hypoglycemic, decrease diabetic auditory neuropathy \\
\hline Gentianine & Anti-inflammatory, anti-diabetic activity \\
\hline Carpaine & Exhibit cardiovascular effect \\
\hline 4-Hydroxyisoleucine & Reduces insulin resistance and body weight \\
\hline Graecunins & Anti-lipidemic activity \\
\hline Yamogenin & Alters lipid accumulation \\
\hline Diosgenin & Hypolipidemic, hypoglycaemic, antioxidant capacity \\
\hline Sarsasapogenin & Anti-tumor activity \\
\hline Protodioscin & Antiproliferative activity \\
\hline Flavonoids (such as quercetin \& rutin) & Antioxidant capacity to combat free radicals \\
\hline Soluble fibres & Controls blood sugar, lowers inflammation \\
\hline Sotolone & Volatile constituent that adds flavour \\
\hline Folic acid & Treats anemia \\
\hline
\end{tabular}

\section{Pharmacological activity of Fenugreek}

Due to the presence of various phytoconstituents in different parts, fenugreek exhibit many pharmacological activities which are summarized in the table -4 . 
International Journal of Ayurvedic Medicine, Vol 12 (4), 776-786

Table 4: Different pharmacological activities of fenugreek

\begin{tabular}{|c|c|c|c|}
\hline S.No. & Pharmacological activity & $\begin{array}{c}\text { Parts of } \\
\text { fenugreek used }\end{array}$ & References \\
\hline 1 & Anti-diabetic activity & Seeds & $\begin{array}{l}\text { Sharma et al., 1990, Morani et al., 2012, Xue et al., 2007, Gupta et } \\
\text { al., } 2001\end{array}$ \\
\hline 2 & Anti-oxidant activity & Leaves and seeds & $\begin{array}{c}\text { Kaviarasan et al., 2007, Annida et al., 2008, Xue et al., 2011, } \\
\text { Tripathi and Chandra } 2009\end{array}$ \\
\hline 3 & Anti-carcinogenic activity & Leaves and seeds & $\begin{array}{l}\text { Hibasami et al., 2003, Sebastian and Thompan 2007, Prabhu and } \\
\text { Krishnamoorthy 2010, Monalic et al., } 2001\end{array}$ \\
\hline 4 & $\begin{array}{l}\text { Anti-inflammatory } \\
\text { activity }\end{array}$ & Seeds and leaves & Kawabata et al., 2011, Sumanth et al., 2006, Vyas et al., 2009 \\
\hline 5 & Anti-lipidemic activity & Leaves and seeds & $\begin{array}{c}\text { Bordia et al., 1997, Abdel-Barry et al., 2000, Sowmya and } \\
\text { Rajyalakshmi } 1999\end{array}$ \\
\hline 6 & Antimicrobial activity & Seeds & $\begin{array}{c}\text { Omolosa and Vagi 2001, Randhir et al., 2004, Olli and Kirti 2006, } \\
\text { Zia et al., } 2001\end{array}$ \\
\hline 7 & Gastroprotective effect & Leaves and seeds & Pandian et al 2002, Al-dalain et al., 2008, Helmy et al., 2011 \\
\hline 8 & Hepatoprotective effect & Leaves and seeds & Kaviarasan et al., 2006, Raju and Bird 2006, Meera et al., 2009 \\
\hline 9 & Anti-cataract activity & Seeds & Gupta SK et al., 2009 \\
\hline 10 & $\begin{array}{l}\text { Effect of Fenugreek on } \\
\text { weight of the body }\end{array}$ & Seeds & Chevassus et al., 2010, Kumar et al., 2014 \\
\hline 11 & Anti-asthamatic activity & Seeds & Schroeter et al., 2002 \\
\hline
\end{tabular}

\section{Anti-diabetic activity}

Diabetes mellitus is a clinical condition disorder that is characterized by persistent rise in blood glucose levels (hyperglycemia). In diabetes, the beta cells of pancreas do not produce sufficient amount of insulin or the body cells are not able to respond to the produced insulin because of insulin resistance. The problem related to diabetes has become a global burden. Polydipsia, Polyuria and Polyphagia are considered hallmarks of diabetes mellitus. Diabetes Mellitus was initially outlined in the Egyptian manuscript 3000 years back (19). Osteoporosis has a strong relevance with diabetes mellitus. During diabetes, there is an abnormal metabolism of carbohydrates leading to increased levels of glucose in the blood.

The use of fenugreek seeds, leaves and extracts has been well established. In many countries such as Saudi Arabia (20), Fenugreek herb was used most commonly to treat diabetes. Various animal and human studies observed the hypoglycemic effects of fenugreek extracts (21) (22). One such study was performed by Sharma et al., on 10 patients having type 1 diabetes. The subjects were given food containing fenugreek seeds powder $(100 \mathrm{~g})$ during lunch and dinner wthin a period of 10 days. At the end of the study there was a great improvement noted in the patients with fenugreek meals including reduction in urine glucose level and reduction of serum glucose levels in fasting conditions (23).

A study conducted by Morani et al., showed ameliorative effects of fenugreek extracts in peripheral neuropathy of rats. IND01 was the fenugreek derived fraction as named by the authors that was standardized and purified by HPLC (high performance liquid chromatography) method. The dose was administered in rats daily over a period of time (particularly 15 days). The motor nerve conduction velocity was restored in rats with sciatic nerve crush injury SNCI. The end results concluded fenugreek extract has neuroprotective activity in painful peripheral neuropathy that is very common in diabetes (24). Another research study by Xue et al., documented the effects of aqueous seed extract of Fenugreek in rats that have STZ-induced diabetes. It was seen that fenugreek treated mice has gained weight as compared to only STZ treated mice. Also there was a great reduction in the blood glucose levels in group that received fenugreek extract as compared to the other one (25). Due to the presence of amino acid (4-hydroxyisoleucine), fenugreek exhibits insulinotropic effect considerably (26). In another clinical study conducted by Gupta et al., on twenty five newly diagnosed type 2 diabetes patients, group I (where $\mathrm{n}=12$ ) received hydroalcoholic extract of fenugreek seeds while group II (where $n=13$ ) received normal care (diet and exercise) along with placebo capsule for a period of two months. It was noted that there was hardly any difference between two groups in terms of values of mean glucose tolerance test except enhancement in insulin sensitivity. It was inferred that adding fenugreek seeds in the diet enhanced blood glucose control as well as reduced insulin resistance in subjects with mild level of type 2 diabetes .(27)

\section{Figure 1: Principle effect of 4-Hydroxyisoleucine and Galactomannan present in fenugreek}

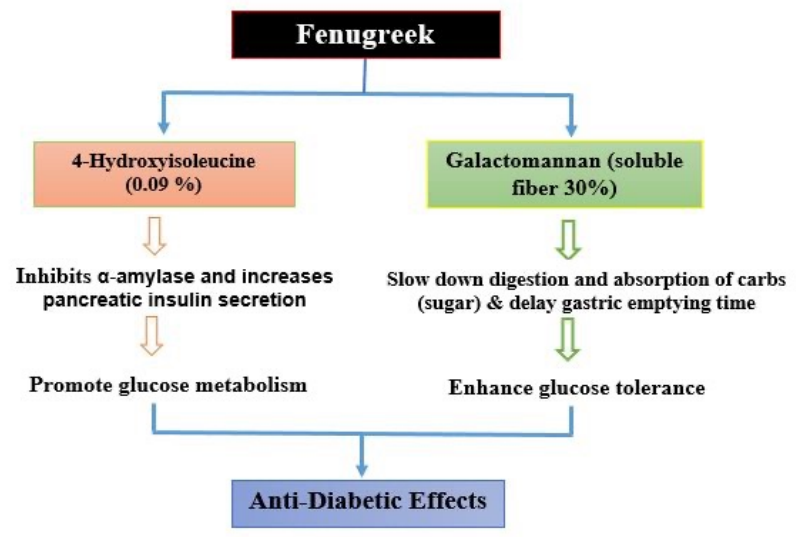




\section{Anti-oxidant activity}

Free radicals are generated during catabolism and metabolism in the human body. Free radicals contain one or more unpaired electrons in outermost shell that makes it extremely unstable or highly reactive. Due to this, they take electrons from other compounds in order to become stable. This makes the attacked molecule to become free radical that finally destroys the living cells (28). The ROS and RNS contribute to cellular damage of the molecules. Free radicals are responsible for fatal diseases like diabetes, cancer, Alzheimer's, etc and may result in tissue damage, inflammation and diseases. To tackle these harmful free radicals, the human body produces naturally occurring products termed as antioxidants. These naturally occurring antioxidants counteract the surplus of free radicals to shield cells and tissues against their deleterious effects. Examples of antioxidants include catalase (CAT), superoxide dismutase (SOD), vitamin $\mathrm{A}, \mathrm{E}$ and $\mathrm{C}$ as well as glutathione reductase (GR) (29) (30).

The phenolic conpounds present in the fenugreek seeds are mainly responsible for anti-oxidant activity (31) (32).Various pharmacological experiments have been conducted by researchers to elucidate the anti-oxidant effect of Fenugreek. Kaviarasan et al., demonstrated the anti-oxidant activity of fenugreek seeds on rat liver and concluded that methanolic extract of fenugreek seeds was able to scavenge the free radicals (33). In another study it is indicated that phenolic compound showed the protective effect of fenugreek seeds. Ethanol was given to induce toxicity in rat liver. The rat liver was treated with the fenugreek seed polyphenol extract $(200 \mathrm{mg} / \mathrm{Kg} /$ day $)$. This caused a notable reduction in protein carbonyl content and lipid peroxidation levels. The activities of antioxidant enzymes were increased and thiol groups were restored (34). Annida et al., demonstrated that in STZ induced diabetic rats, oxidative stress was notably reduced due to supplementations of fenugreek leaves. It was also concluded that admiration of Fenugreek leaf powder to diabetic rats lowered lipid peroxidation at the same time elevated the antioxidant system (35).

Xue et al., observed the antioxidant potential of aqueous extract of Fenugreek seeds in reinstating kidney function of diabetic rats. When the diabetic rats were treated with Fenugreek extract, there was an elevation in the activities of SOD and catalase and reduction in the concentration of malondialdehyde (MDA) in serum and diabetic rats kidney. Also, noted was a decrease in the levels of 8-hydroxy-2'deoxyguanosine in urine (an indicator of increased oxidative stress). These investigations elucidated the protective action of Fenugreek extract by remarkably increasing the antioxidant enzyme activities in kidney of diabetic rats (36). Tripathi and Chandra conducted a similar study that concluded Fenugreek significantly improved Thiobarbituric acid reactive substances (TBARS) levels and antioxidant enzyme activities in various tissues such as kidney, liver or heart enunciating antioxidant effect of fenugreek in diabetes induced oxidative stress (37).

\section{Anti-carcinogenic activity / Chemopreventive} Activity

Cancer is an uncontrolled growth of cells resulting in the formation of tumors in body. Cancer is not a single disease but a group of many distinctive lethal diseases with high mortality rate. Many in vitro and in vivo studies were conducted to highlight the anticarcinogenic potential of Fenugreek seeds in experimental animals. Phytoestrogens and saponins are the chief phytoconstituents of fenugreek responsible for anti-carcinogenic activity (38). Constituents like Diosgenin, Protodioscin and trigonellene (alkaloids) have been revealed to have anti-cancer activity.

In a study by Hibasami et al., protodioscin (a furostanol saponin derived from fenugreek) exhibited death in leukemic cell line (HL-60) in account for apoptotic alterations (39). Sebastian and Thompan, in an investigation, demonstrated that ethanolic extract of Fenugreek decreased cell viability (functioning) and cause apoptotic changes like decrease in mitochondrial membrane potential as well as inversion of phosphatidylserine. Also it is observed that DNA were degraded into multiple fragments. Further, cell cycle was observed to be arrested at $\mathrm{G} 2 / \mathrm{M}$ phase and showed a sub-G1 apoptotic population in cells treated with Fenugreek extract suggesting apoptosis induced by Fenugreek repressing anticancer potential (40). Prabhu and Krishnamoorthy, in one of the investigation, injected Swiss albino mice with EAC to illustrate anticancer activity of Trigonella leaf ethanolic extract. The mice showed enhanced lifespan when compared with tumor control indicating anticancer potential of fenugreek extract in animal models (41). Monalic et al., demonstrated the repressing effect of diosgenin on human osteosarcoma cell line (1547 cell line). This was attributed due to the halt of cell cycle at G1 and initiation of apoptosis process (42).

\section{Anti-inflammatory activity}

Inflammation is defensive mechanism of our body. There are five hallmark cardinal signs of inflammation such as calor (heat), tumor (swelling), rubor (redness), dolar (pain) and functio laesa (loss of function). Fenugreek seeds contain alkaloids (43), saponins and flavonoids (44) that play a pivotal role as an anti-inflammatory agent.

Many experiments have been conducted to elucidate the anti-inflammatory potential of fenugreek seeds. Kawabata et al., studied anti-inflammatory potential of fenugreek seeds in human monocytic cell line (THP-1). 12-o-tetradecanoylphorbol-13-acetate was used to induce inflammatory cytokines such as IL-1, IL-6 and TNF-a. The methanolic extract of Fenugreek caused repression in production of TNF-a. This extract was further examined for isolation and segregation of functionalized compounds like saponins and related compounds that caused inhibition of other cytokines like IL-1 and IL-6 as well as TNF-a (45). Sumanth et al., reported anti-inflammatory potential of Trigonella against ulcer production.To induce ulcers in rats, Indomethacin and immersion stress was used. Antiulcer effect was exhibited by aqueous extract of 
fenugreek determined by the ulcer index (46). The protective effect of the extract against ulcer was allocated to the anti-oxidants present in them. The leaves also exhibit antipyretic and anti-inflammatory activity (47). Vyas et al., reported the analgesic and antiinflammatory activity of purified fraction of fenugreek seed extract. The pain was induced both by acetic acid and hot plate in a mouse model. When the experimental data was compared with control group, the group treated with fenugreek extract showed notable dose dependent analgesic activity (48).

\section{Anti-lipidemic activity / Hypocholesterolemic activity}

Cholesterol is a type of lipid molecule that mainly constitutes the animal cell membranes. Atherosclerosis is a serious condition resulting from cholesterol plaques in the walls of the arteries. This causes arteries to become narrow resulting in reduced blood flow through arteries and causing serious cardiovascular diseases. Oxidative alteration of low density lipoprotein (LDL) is considered a critical incident in the pathogenesis of atherosclerosis (49). The prevalence of high levels of cholesterol in blood plasma increase risk for atherosclerotic heart disease. It is very important to manage cholesterol levels to prevent cardiovascular diseases by hampering the increasing atherosclerosis in hyperlipidemic individuals. It is assumed that if lipid levels (triglycerides and LDLcholesterol) are managed, it results in preventing chronic inflammatory diseases.

There is enough data to suggest that fenugreek decreases serum cholesterol. Various pharmacological experiments have been performed on animal models. The animal experimentation is not just restricted to rats and mice but is also performed on different species of rabbits and dogs as well. Bordia et al., conducted a study involving coronary artery disease (CAD) either with or without type - 2 diabetes. Fenugreek was given twice a day for around three months at a dose $2.5 \mathrm{~g}$ to both the individuals (groups). While healthy individuals revealed no specific effect on lipid profile, the CAD patients remarkably had decrease in blood lipids, total cholesterol and triglycerides with no estimated effect on HDL-cholesterol (50). Abdel-Barry et al., conducted a study on 20 healthy male volunteers. A single dose of aqueous extract of fenugreek leaves $(40 \mathrm{mg} / \mathrm{kg})$ was given. A dilute coffee extract was used as placebo. There was a reduction of $9.2 \%$ in total serum cholesterol as compared to reduction of $2.8 \%$ of placebo group (51). Sowmya and Rajyalakshmi conducted a study on 20 adults having hypercholesterolemia. These adults received a dose of 12.5 - $18.0 \mathrm{gm}$ of powdered fenugreek seeds for a duration of one month. It was seen that there was a significant decrement in both total cholesterol and low density lipoprotein cholesterol (LDL-C) (52). A compound termed GII isolated from fenugreek seed extract with water was found to show changes in serum lipid levels in diabetes induced rabbits. The compound showed incredible effect by reducing total cholesterol (triacylglycerols, phospholipids and free fatty acids) while increasing HDL cholesterol (53). It is also indicated that diosgenin (a steroidal saponin present in fenugreek) reduces hypercholesterolemia in monkeys. Diosgenin has a wonderful effect on cholesterol metabolism leading to lower cholesterol concentration in plasma. In general, the plant protein content present in fenugreek is $26 \%$ that has cholesterol lowering capacity (54). The hypocholesterolemic activity of fenugreek may be accounted to its estrogenic constituent (55), saponins (diosgenin) and fiber. The proposed mechanism through which saponins act is by enhancing biliary cholesterol excretion resulting in lower cholesterol serum levels (56) (57).

\section{Antimicrobial activity}

Micro-organism include bacteria, viruses, fungi, algae and protozoa. These tiny organisms are present all over the world and even within our human body. Herbs have been used globally for their antimicrobial activity. Plant systems like Curcuma longa, Citrus lemon and many more are studied by researchers that showed intense microbial activities. The antibacterial activity of various plant extracts may be partially attributed to different phytoconstituents present in fenugreek such as phenolic compounds, alkaloids, flavonoids, tannins, steroids, saponins, etc.

Various studies have highlighted the antibacterial as well as antifungal activities of fenugreek seeds. Many studies were conducted that showed various parts of fenugreek plant like leaves, roots and stem exhibited antifungal potential against fungal strains such as Rhizoctonia solani, Fusarium graminearum, Botrytis cinerea and Alternaria sp, (58). In a study documented by Omolosa and Vagi, Fenugreek has shown intense microbial activity against 26 bacterial pathogens (59). Fenugreek has also shown high antimicrobial activity against Helicobacter pylori as documented by Randhir et al., Fenugreek sprout extract was used that contains free phenolic content showing more antimicrobial activity (60). In a study by Olli and Kirti, small cycsteine rich peptides named Tfgd1 was successfully cloned having antifungal effect. The expressed protein recombinant in E.coli showed great antifungal activity against wide range of fungi like Phaeoiusariopsis personata and $R$. solani (61). Zia et al demonstrated nematicidal effect of Fenugreek methanol fraction extract on Meloidogyne javanica larvae accounting for death of the larvae (62). Antimycotic activity of fatty oil of fenugreek against Aspergillus fumigates and Aspergillus niger was also reported (63).

\section{Gastroprotective effect}

Gastric ulcers occur when there is damage to the inner lining of the stomach or small intestine. A bacterium like $\mathrm{H}$. pylori present in digestive tract is a common cause of gastric ulcer. Fenugreek was traditionally used in the management of gastric ulcer. The fenugreek seed oil extract exhibit pharmacological activities that have been studied by the scientists globally. In one such research, it is indicated that fenugreek exhibits ulcer protective activity against ethanol induced gastric ulcer in rats. The activity of 
fenugreek was compared with that of omeprazole. Aqueous extract of fenugreek showed great ulcer protectiveness when compared to omeprazole. The erosion of mucosal layer caused by ethanol due to the lipid peroxidation is prevented by fenugreek seeds. This is due to increasing antioxidant capacity of gastric mucosa resulting in minimal injury to mucosal layer (64). In another study performed on Albino rats, aspirin $(400 \mathrm{mg} / \mathrm{kg})$ was given to induce ulcer. Then aqueous extracts of Trigonella foenum graecum L (fenugreek) and Hordeum vulgare L (barley grains) was given to the same group. The end result showed that rats treated with aqueous extract showed great decrease in ulcer severity which is calculated by curative ratio and ulcer index and confirmed histopathologically (65). In a similar study performed on rats, Aspegic was given to induce gastric mucosal ulcer. Fenugreek was administred that showed great anti-ulcer potential in rats (66). This action may be due to the presence of flavonoids content in fenugreek that prevents necrotic agents to form ulcerative lesions (67) (68). Chemical constituents like trigonelline, phytic acid and saponins are responsible for lessening gastric ulcer (69).

\section{Hepatoprotective effect}

Hepatotoxicity or toxic hepatitis refers to damage to the liver that may be attributed to many factors including drug-induced injury. Damage to liver may affect people of all ages. Alcohol addiction and long term alcoholism is the leading cause linked with liver diseases and fibrosis (70) (71). Many medicines and drugs could also contribute to hepatic damage. That is why it becomes very essential to have a proper knowledge of herbs and extract many properties including hepatoprotective activity of plant based medicines (72). Kaviarasan et al., conducted a study in human Chang liver cells. The cells were exposed to ethanol. This induced cytotoxicity, mitochondrial dysfunction, concentration of GSSG (oxidized glutathione) and reduced growth of Chang liver cells. There was also decrease in GSH level when compared to normal cells. Polyphenolic content present in the extract of fenugreek was used along with ethanol. Cells were incubated with this aqueous extract that resulted in increased cell viability. It also decreased TBARS formation, lactate dehydrogenase leakage and GSH/ GSSH ratio was normalized. Silymarin (a hepatoprotective substance) and effects of FPEt are comparable (73). Raju and Bird performed a study on $\mathrm{Ob}$ rats. The rats were given fenugreek diet. The end result showed reduction in triglyceride and soluble or bound forms of TNF-a when compared to control group. This highlights that there was a decrease in triglyceride accumulation in liver after fenugreek administration (74). Meera et al., in a study demonstrated on goat model demonstrated the hepatoprotective effect and antilipid peroxidation effect of ethanol fenugreek extract. $\mathrm{H} 2 \mathrm{O} 2$ and $\mathrm{CCl} 4$ was used to induce liver damage in goat model. Hepatoprotective effect was observed as there was seen reduced levels of enzymatic as well as non-enzymatic antioxidant enzymes (75).

\section{Anti-cataract activity}

Cataract is a serious medical issue that affects the vision of the eye resulting in cloudy lens. Cataract decreases the normal vision of a person. It can result from either aging or trauma. Around $90 \%$ of the people by the age of sixty five are affected by this condition. Factors such as obesity, smoking, steroids, high B.P., nitric oxide, etc could account for the growth of cataract (76). Various experimental studies were performed to highlight the anti-cataract effect of Fenugreek seeds. One such study was performed in selenite induced cataract. In an organ culture that has Dulbecco's modified Eagles medium (DMEM) and $100 \mathrm{uM}$ selenite as standard and control group, rat enucleated lenses were kept. In case of the test group, selenite and Fenugreek aqueous extract was served in medium and lens was incubated at a temperature of $37 \mathrm{oC}$ for 24 hour. Then reduced glutathione (GSH), anti-oxidant enzyme and lipid peroxidation product (malondialdehyde) was estimated. A rise in malondialdehyde and reduction in GSH in control when compared to standard lenses was observed. Fenugreek extract greatly reinstated glutathione and reduced the malondialdehyde levels. In Fenugreek supplemented group, effects of various antioxidant enzymes like superoxide dismutase, glutathione peroxide and catalase were restored. The anti-cataract effect was attributed to antioxidant activity of aqueous Fenugreek extract. It was also observed that GSH levels were decreased in selenite presence as well as anti-oxidant enzymes were also reduced (77).

\section{Effect of Fenugreek on weight of the body}

Obesity is a common problem worldwide. With increasing population there is increasing demand of food all over the world. This increasing demand of food comes under two categories, i.e., healthy nutrition and unhealthy nutrition. Too much craving of unhealthy food and nutrition could result in increased body weight and obesity. According to WHO, the individuals having Body Mass Index (BMI) equal to or greater than 25 is considered to be obese. Many studies concluded that extract of Fenugreek as supplement reduced the body weight and adipose tissue weight (78) (79). One such randomized placebo controlled trial study was conducted for 6 weeks on 39 overweight healthy male subjects given a fixed dose of extract of fenugreek seeds. It was noted that frequent administration of the extract resulted in reduced dietary fat consumption in the given subjects (80). The possible mechanism through which fenugreek acts is twofold. Firstly, fenugreek expels the carbohydrate contents from the body just before it can enter the blood stream causing loss of weight, furthermore fenugreek has a significant amount of soluble fiber (around 40\%) that basically slows down the digestion and absorption of carbohydrates from the intestine thus indirectly suppressing hunger and encouraging weight loss (81). The amino acid named 4-hydroxyisoleucine $(0.015 \%$ $0.4 \%$ ) present in fenugreek reduces plasma triglyceride gain resulting in weight loss and prevention of obesity (82). In one of the experiments, it was observed that 
aqueous extract of fenugreek given to rats on high fat diet showed decrease in body weight and also in body mass index. Also a sudden reduction in biochemical parameters including serum lipid profile and cardiac elements were noted. The level of leptin was also reduced in adipose tissue by fenugreek (83).

\section{Effect in treatment of Asthma}

Asthma is a respiratory disorder that affects the bronchi of lungs resulting in spasm and causing difficulty in inhalation and exhalation process. Asthma causes inflammation of the bronchial tubes resulting in narrowing of the pathway. Many studies were performed to check the extent to which fenugreek extract helps provided as supplement. In various studies, the present of flavonoids content in fenugreek can limit the lipid peroxidation as well as protect the respiratory tract from unnecessary oxidative stress (84). The mechanism of action against asthma is very little known but flavonoids in fenugreek up to certain extent can limit the stimulation of basophile cells and mast cells (85). Fenugreek's antioxidant capacity as well as the occurrence of flavonoids (quercetin) can prevent the emergence of crystals of Charcot-Leyden which are the characteristics in asthmatic patients. Fenugreek also has the capacity to reduce the stress caused by oxidative mediators (86). It has also been well established that fenugreek seeds have diverse effect as an antiinflammatory agent (87). Fenugreek seeds have high content of mucilage around $28 \%$ due to the presence of which there is comfort in the secretions of lungs. This could also account for mechanism of action. In one experimental study where one group was given fenugreek and other group was given honey as intervention, it was found that the efficacy of fenugreek was much high. Even clinical studies were conducted to demonstrate the effect of fenugreek seeds on asthma (88). It is very clear that fenugreek is highly effective in treatment of mild asthma without producing any side effects. Also fenugreek helps to improve the functions of respiratory tract as well as lungs.

\section{Medicinal uses}

Fenugreek is considered a multipurpose crop. From maintaining the blood glucose level to having anti-bacterial and anti-fungal effects, fenugreek is critically important for keeping a healthy digestive system. Fenugreek had diverse ethno-historical uses. Traditionally, fenugreek was used as a potent aphrodisiac to increase sexual desire and performance. Fenugreek was also used by Egyptian women to lessen menstrual pain and stomach problems (89). Fenugreek seeds were considered as a hypoglycemic agent in Egyptian folk medicine. In Chinese medicine system, fenugreek was used as a tonic and to treat leg frailty and edema (90). Fenugreek was recognized as a main component for treating dysmenorrheal and postmenopausal symptoms. In folk medicines, fenugreek was used for the treatment of tuberculosis and boils. The seeds of fenugreek were also used as a herbal remedy for constipation and diarrhea (91) (92). The alcoholic extract of fenugreek was used to expel unwanted harmful material or poisons from the human body (93).

Presently, fenugreek is used for diverse purposes across the globe such as for preparing flavor cleanse in Switzerland, spice in Iran, as vegetables in India and Pakistan and seed powder along with flour for making flat bread in Egypt (94). Fenugreek have well established role in treating various animal and human disorders (95). For instance the seed of fenugreek was used to enhance milk production (96) and lower serum cholesterol level (97) in animals. Fenugreek is also used as food preservative in pickles as well as sauces. A wellknown advantage of fenugreek is that it enhances blood hemoglobin level through natural means. This could help manage anemia and lead a long and healthy life (98). The seeds of fenugreek is used as a tonic and carminative as well as in several conditions like to treat dyspepsia, to cure skin conditions (wounds, psoriasis, rashes), treatment of reproductive disorders, gout, chronic cough, heavy metal toxicity and in rheumatism (99) (100).

Figure 2: Health Impact of Fenugreek

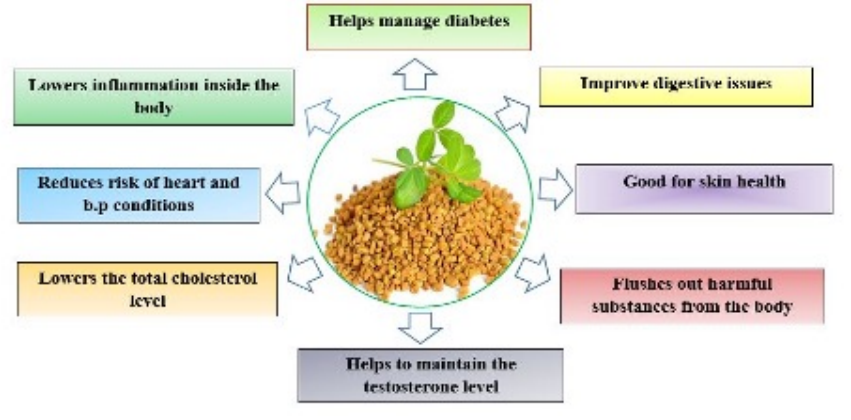

\section{Summary}

In this review, promising pharmacological aspects and properties of fenugreek and its parts such as seeds and leaves are highlighted. Ethno-historical uses and modern medicinal value of fenugreek are also covered. Diverse bioactive constituents such as alkaloids, flavonoids, saponins, dietary fibres and many more are of great pharmacological importance. This review would help world researchers to find concise information regarding fenugreek as a future scope for nutrition and good health.

\section{References}

1. Kirtikar and Basu; "Indian Medicinal plants" International Book Distributors, 9/3, Rajpur Road (Ist floor) Dehradun-248001, India, Vol. I, Page. No.700-701.

2. "The Ayurvedic Pharmacopoeia of India", Part- I, volume II, First edition, Govt. of India Ministry of health Education, Page No. 107-108.

3. Acharya SN, Thomas JE, Basu SK. Fenugreek: An "old world" crop for the "new w o r $1 \mathrm{~d}$ ". Biodiversity. 2006; 7(3\&4): 27-30. DOI: 10.1080/14888386.2006.9712808

4. Acharya SN, Blade S, Mir Z., Moyer JS. Tristar fenugreek. Canadian Journal of Plant

Science. 2007; 87: 901-903. DOI: 10.4141/ P06-047. 
Veer Inder Singh et.al., Pharmacological aspects \& medicinal uses of Trigonella foenum-graecum: A Current Review

5. Im KK, Maliakel BP. Fenugreek dietary fibre a novel class of functional food ingre di e $\mathrm{nt}$. Agro Food Ind Hi Tec. 2008;19(2):18-21.

6. Acharya S, Srichamroen A, Basu S, Ooraikul B, Basu T. Improvement in the nutraceutical properties of fenugreek (Trigonella foenum-graecum L.). Songklanakarin Journal of Science and Technology. 2006; 28(1): 1-9.

7. Basu SK. Seed production technology for fenugreek (Trigonella foenum-graecum L.) in the Canadian (Master of Science thesis). Lethbridge, Alberta, Canada: Department of Biological Sciences University; 2006.

8. Petropoulos GA. Fenugreek, The Genus Trigonella. London and New York: Taylor and Francis; 2002. $255 \mathrm{p}$.

9. Chatterjee A, Prakashi SC (eds) Treatise on Indian medicinal plants, Vol. 2. Council of Scientific and Industrial Research, New Delhi; 1995

10. Mehrafarin A, Qaderi A, Rezazadeh Sh, Naghdi Badi H, Noormohammadi Gh, Zand E

Bioengineering of important secondary metabolites and metabolic pathways in fenugreek (Trigonella foenum graecum L.). Journal of Medicinal Plants. 2010; 9(35): $\quad 1-18$.

11. Dini M. Scientific Name of Medicinal Plants Used in Traditional Medicine. Tehran, Iran: Forest and Rangeland Research Institute; 2006:299.

12. Ravi kumar, P., \& Anuradha, C. V., Effect of fenugreek seeds on blood lipid peroxidation and antioxidants in diabetic rats. Phytotherapy Research;1999, 13,1-5.

13. Kaviarasan, S., Vijayalakshmi, K., \& Anuradha, C. $\mathrm{V}$. A polyphenol-rich extract of fenugreek seeds protect erythrocytes from oxidative damage. Plant Foods for Human Nutrition; 2004 59, 143-147.

14. Anis M, Aminuddin E. Estimation of diosgenin in seeds of induced autoploid Trigonella foenum graecum. Fitotrapia. 1985;56:51-52.

15. Varshney IP, Sharma SC. Saponins XXXII: Trigonella foenum graecum seeds. J Indian $\mathrm{Ch}$ e m Soc. 1996;43:564-567.

16. Rao, A.V., Herbal Cure for Common Diseases. Fusion Books, New Delhi 2003.

17. Yadav, S., Sehgal, S., Effect of home processing and storage onascorbic acid and B-carotene content of bathua (Chenopodiumalbum) and fenugreek (Trigonellafoenum graecum) leaves. PlantFood Hum. Nutr; 1997.50, 239-247.

18. Sowmya, P., Rajyalakshmi, P., Hypocholesterolemic effect ofgerminated fenugreek seeds in human subjects. Plant Food Hum. Nutr;1999. 53, 359-365.

19. Ahmed AM. History of diabetes mellitus. Saudi Med J 2002 Apr;23(4):373-378

20. Al- Rowais NA. Herbal medicine in the treatment of diabetes mellitus. Saudi Medical Journal 2002; 23:1327-1331.

21. Broca C, Gross R, Petit P, Sauvaire Y, Manteghetti M, Tournier M, et al. 4 Hydroxyisoleucine: experimental evidence of its insulinotropic and antidiabetic properties. Am J Physiol Endocrinol Metab 2004; 287(3): E463-471.

22. Al-Khateeb E, Hamadi SA, AlHakeemi AAN, and Abu-Taha M, AlRawi N. Hypoglycemic effect of trigonelline isolated from Iraqi Fenugugreek seeds in normal and Alloxan-diabetic rabbits. European Scientific Journal 2012; 8(3). (Online).

23. Sharma RD and Raghuram TC. Hypoglycaemic effect of fenugreek seeds in non-insulin dependent diabetic subjects. Nutr Res 1990; 10: 731-739.

24. Morani AS, Bodhankar SL, Mohan V, Thakurdesai PA. Ameliorative effects of standardized extract from Trigonella foenum-graecum L. seeds on painful peripheraly in rats. Asian Pac J Trop Med; 2012. 5:385-90.

25. W.-L. Xue, X.-S. Li, J. Zhang, Y.-H. Liu, Z.-L. Wang, and R.- J. Zhang, "Effect of Trig o n e lla foenum-graecum (Fenugreek) extract on blood glucose, blood lipid and he morh e o log i c a l properties in streptozotocin-induced diabetic rats," Asia Pacific Journal of Clinical Nutrition, vol. 16, no. 1, pp. 422-426, 2007.

26. Haefele C, Bonfils C, Sauvaire Y., Characterization of a dioxygenase from Trigonella foenumgraecum involved in 4-hydroxyisoleucine biosynthesis. $\quad$ Phytochemistry; 1997 44(4):563-6.

27. Gupta A, Gupta R and Lal B. Effect of Trigonella foenum-graecum (fenugreek) seeds on glycaemic control and insulin resistance in type 2 diabetes mellitus: a double blind placebo controlled study. J Assoc Physicians India 2001; 49:1057-1061.

28. Mukherji SM, Singh SP. Reaction mechanism in organic chemistry. Madras: Macmillan IndiaPress; 1986.

29. Willcox JK, Ash SL, Catignani GL. Antioxidants and prevention of chronic disease. Review. Crit. Rev. Food. Sci. Nutr. 2004; 44: 275-295.

30. Valko M, Rhodes CJ, Moncol J, Izakovic M, et al. Free radicals, metals and antioxidants in oxidative stress-induced cancer. Mini-review. Chem. Biol. Interact. 2006; 160: 1-40.

31. Kaviarasan S, Naik GH, Gangabhagirathi R, Anuradha W, Priyadarsini KI,In vitro studies on anti radical and antioxidant activities of fenugreek (Trigonella foenum $\mathrm{g} \mathrm{r}$ a e c u m ) seeds, Food Chemistry, 103, 2006, 31-37.

32. Anuradha CV, Ravikumar P, Restoration on tissue antioxidants by fenugreek seeds ( T. fo e n u m graecum) in alloxan-diabetic rats, Ind. J. Physiol. Pharmacol, 45, 2001, 408-420.

33. Kaviarasan S., G. H. Naik, R. Gangabhagirathi, C. V. Anuradha, and K. I. Priyadarsini, "In vitro studies on antiradical and antioxidant activity of (Trigonella foenum graecum) fenugreek seeds," Food Chemistry, vol. 103, pp. 31-37, 2007.

34. Kaviarasan S, R. Sundarapandiyan, and C. V. Anuradha, "Protective action of f e n u g r e e k (Trigonella foenum graecum) seed polyphenols against alcohol-induced protein and lipid 
damage in rat liver," Cell Biology and Toxicology, vol. 24, no. 5, pp. 391-400, 2008.

35. Annida B, Stanely Mainzen, Prince P., Supplementation of fenugreek leaves reduces oxidative stress in streptozotocin-induced diabetic rats. J Med Food; 2005.8:382-5.

36. Xue W, Lei J, Li X, Zhang R. , Trigonella foenumgraecum seed extract protects function and morphology in diabetic rats via its antioxidant activity. Nutr Res; $2011 \quad 31: 555-62$.

37. Tripathi UN, Chandra D. , The plant extracts of Momordica charantia and Trigonella foenumgraecum have antioxidant and antihyperglycemic properties for cardiac tissue during diabetes mellitus. Oxid Med Cell Longev; 2009, 2:290-6.

38. Raju J, J. M. R. Patlolla, M. V. Swamy, and C. V. Rao, "Diosgenin, a steroid saponin of Trigonella foenum graecum (Fenugreek), inhibits azoxymethane-induced aberrant crypt foci formation in F344 rats and induces apoptosis in HT-29 human colon cancer c e $11 \mathrm{~s}$, , C a n c e r Epidemiology Biomarkers and Prevention, vol. 13, no. 8, pp. 1392-1398, 2004.

39. Hibasami H, Moteki H, Ishikawa $\mathrm{K}$, et al. Protodioscin isolated from fenugreek

(Trigonella foenum-graecum L.) induces cell death and morphological change indicative $o \mathrm{f}$ apoptosis in leukemic cell line H-60, but not in gastric cancer cell line KATO III. Int J Mol Med ; 2003.11:23-6.

40. Sebastian KS, Thampan RV., Differential effects of soybean and fenugreek extracts on the growth of MCF-7 cells. Chem Biol Interact; 2007. 170:135-43.

41. Prabhu A, Krishnamoorthy M., Anticancer activity of Trigonella foenum- graecum on Ehrlich Ascites carcinoma in Mus musculus system. J Pharm Res; 2010. 3:1181-3.

42. Moalic S, B. Liagre, C. Corbiere et al., "A plant steroid, diosgenin, induces apoptosis, cell cycle arrest and COX activity in osteosarcoma cells," FEBS Letters, vol. 506, no. 3, pp. 225-230, 2001.

43. Shang M, Cai S, Han J, Li J, Zhao Y, Zheng J, Namba T, Kadota S, Tezuka Y, Fan W. Studies on flavonoids from Fenugreek (Trigonella foenum graecum). Zhongguo Zhong Yao Za Zhi 1998;23: 614-6.

44. Raju J, Patlolla JMR, Swamy MV, Rao CV. Diosgenin, a steroid saponin of Trigonella foenum gra e cum (Fenugreek), inhibits azoxymethaneinduced aberrant crypt foci formation in F344 rats and induces apoptosis in HT-29 human colon cancer cells. Cancer Epidemiol Biomarkers Prev 2004; 13: 1392-8.

45. Kawabata T, M.-Y. Cui, T. Hasegawa, F. Takano, and T. Ohta, "Anti-inflammatory a n d a n t i melanogenic steroidal saponin glycosides from fenugreek (Trigonella foenum graecum L.) seeds," Planta Medica, vol. 77, no. 7, pp. 705-710, 2011.

46. Raju J and R. P. Bird, "Alleviation of hepatic steatosis accompanied by modulation of plasma and liver TNF- $\alpha$ levels by Trigonella foenum graecum (fenugreek) seeds in Zucker obese (fa/fa) rats," International Journal of Obesity, vol. 30, no. 8, pp. 1298-1307, 2006.

47. Sumanth M, P. Kapil, and P. Mihir, "Screening of aqueous extract of Trigonella f o e $n u$ m graecum seeds for its antiulcer activity," International Journal of Research in Pharmaceutical and Biomedical Sciences, vol. 2, no. 3, pp. 10851089, 2011.

48. Vyas S, Agrawal RP, Solanki P, Trivedi P., Analgesic and anti-inflammatory activities of Trigonella foenum-graecum (seed) extract. Acta Pol Pharm; 2008. 65:473-6.

49. Witztum JL, Steinberg D, The oxidative modification hypothesis of atherosclerosis. Does it hold for humans? Trend Cardiovasc Med, 11, 2001, 93-102.

50. Bordia A, Verma SK, Srivastava KC., Effect of ginger (Zingiber officinale Rosc.) and fenugreek (Trigonella foenum-graecum L.) on blood lipids, blood sugar and platelet aggregation in patients with coronary artery disease. Prostaglandins Leukot Essent Fatty Acids; 1997. 56:379-84.

51. Abdel-Barry JA, Abdel-Hassan IA and Al-Hakiem MHH. Hypoglycaemic effect of a q u e o u s extract of the leaves of Trigonella foenum-graecum in healthy volunteers. Eastern Mediterranean Health Journal 2000; 6(1): 83-88.

52. Sow y a P and Rajyalakshmi P. Hypocholesterolemic effect of germinated fenugreek seeds in human subjects. Plant Foods Hum Nutr 1999;53:359-365.

53. Moorthy R, K. M. Prabhu, and P. S. Murthy, "Antihyperglycemic compound (GII) from fenugreek (Trigonella foenumgraecum linn.) seeds, its purification and effect in diabetes mellitus," Indian Journal of Experimental Biology, vol. 48, no. 11, pp. 1111-1118, 2010.

54. Sharma RD. Effects of fenugreek seeds and leaves on blood glucose and serum insulin responses in human subjects. Nutr Res. 1986; 6: 1353-64.

55. Sauvaire Y, Ribes G, Baccou JC, et al. Implication of steroid saponins and sapogenins in th e hypocholesterolemic effect of fenugreek. Lipids 1991;26:191-197.

56. AlHabori M, AlAghbari AM, Al-Mamary M. Effects of fenugreek seeds and its extracts on plasma lipid profile: a study on rabbits. Phytother Res 1998;12:572-575.

57. AlHabori M, Raman A. Antidiabetic and hypocholesterolaemic effects of fenugreek.

Phytother Res 1998; 12:233-242.

58. Haouala R, Hawala S, El-Ayeb A, et al., Aqueous and organic extracts of Trigonella foenumgraecum L. inhibit the mycelia growth of fungi. J Environ Sci (China); 2008 20:1453-7

59. Omolosa AD and Vagi JK. Broadspectrum antibacterial activity of Trigonella foenumgraecum. Nat. Prod. Sci. 2001;7(1): 13-16. 
Veer Inder Singh et.al., Pharmacological aspects \& medicinal uses of Trigonella foenum-graecum: A Current Review

60. Randhir R, Lin YT and Shetty K. Phenolics, their antioxidant and antimicrobial activity in dark germinated fenugreek sprouts in response to peptide and phytochemical elicitors. Asia Pac J Clin Nutr 2004;13 (3):295-307.

61. Olli S, Kirti PB. Cloning, characterization and antifungal activity of defensin Tfgd1 from Trigonella foenum-graecum L. J Biochem Mol Biol ; 2006.39:278-83

62. Zia T, Hasnain SN, Hasan SK., Evaluation of the oral hypoglycaemic effect of Trigonella foenumgraecum L. (methi) in normal mice. J Ethnopharmacol; 2001 75:191-5.

63. Wagh P, Rai M, Deshmukh SK and Durate MCT. Bio-activity of oils of Trigonella f o e $n u m$ graecum and Pongamia pinnata. African Journal of Biotechnology 2007; $6 \quad$ (13):1592- 1596.

64. Pandian RS, Anuradha CV and Viswanathan P. Gastroprotective effect of fenugreek s e e d s (Trigonella foenum- graecum) on experimental gastric ulcer in rats. J Ethnopharmacol. 2002;81(3):393-397.

65. Al-dalain S, El-kutry M and Ibrahim HS. Inhibitory Effect of Aqueous Extracts of Barley and Fenugreek on Ulcer Induction in Rats. World Applied Sciences Journal 2008;5(3): 332-339.

66. Helmy HM. Study the Effect of Fenugreek Seeds on Gastric Ulcer in Experimental Rats. World Journal of Dairy \& Food Sciences 2011;6(2): 152-158.

67. Gálvez J, De Medina FS, Jiménez J and Zarzuelo A. Effects of flavonoids on gas trointestinal disorders. Studies in natural products chemistry 2001; 25: 607-649.

68. Choi SM, Shin JH, Kang KK, Ahn BO and Yoo M. Gastroprotective effects of D A-6034, a new flavonoid derivative, in various gastric mucosal damage models. Dig D i s S c i . 2007;52(11):3075-3080.

69. Kamel MA, R. Z. Hamza, N. E. Abdel-Hamid, and

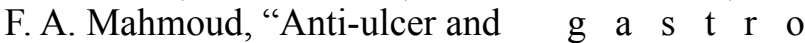
protective effects of fenugreek, ginger and peppermint oils in experimentally induced gastric ulcer in rats," Journal of Chemical and Pharmaceutical Research, vol. 6, no. 2, pp. 451468, 2014.

70. Bellentani S, Saccoccio G, Costa G, et al. . Drinking habits as cofactors of risk for alcohol induced liver damage. The Dionysos Study Group. Gut; 1997. 41:845-50.

71. Patsenker E, Stoll M, Millonig G, et al., Cannabinoid receptor type I modulates

alcohol-induced liver fibrosis. Mol Med; 2011. 17:1285-94.

72. Alvari A, Ohadi Rafsanjani MS, Ahmad FJ, Abdin MZ. ,Current status and future prospects of hepatoprotective herbal medicines: Contemporary overview into the clinical trials. Rev Recent Clin Trials; 2012. 7:214-23.

73. Kaviarasan S, Ramamurty N, Gunasekaran P, et al. Fenugreek (Trigonella foenum-graecum) seed extract prevents ethanol-induced toxicity and apoptosis in Chang liver cells. Alcohol Alcohol; 2006. 41: 267-73.

74. Raju J, Bird RP. ,Alleviation of hepatic steatosis accompanied by modulation of plasma and liver TNF-alpha levels by Trigonella foenumgraecum (fenugreek) seeds in Zucker obese (fa/fa) rats. Int J Obese (Lond); 2006 30:1298-307.

75. Meera R, Devi P, Kameswari B, et al. (2009). Antioxidant and hepatoprotective activities of Ocimum basilicum Linn. and Trigonella foenumgraecum Linn. against $\mathrm{H} 2 \mathrm{O} 2$ and $\mathrm{CCl} 4$ induced hepatotoxicity in goat liver. Indian J Exp Biol; 2009. 47:584-90.

76. Varma SD, Kavita RH, Susceptibility of the ocular lens to nitric oxide: implications in cataractogenesis, J Ocular Pharmacol Therap, 23, 2007, 188-195.

77. Gupta SK, Kalaiselvam V, Srivasta S, Saxena R, Agarwal SS,Trigonella foenum $\mathrm{g} \mathrm{r}$ a e c u m (fenugreek) protects against selenite-Induced oxidative stress in experimental cataractogenesis, Biol Trace Elem Res, 136, 2009, 258-268.

78. Handa T, Yamaguchi K, Sono $\mathrm{Y}$ and Yazawa $\mathrm{K}$. Effects of fenugreek seed extract in obese mice fed a high-fat diet. Biosci.Biotechbol.Biochem 2005; 69(6):1186-1188.

79. Geetha M, Suneel KR, Krupanidhi AM, Muralikrishna K S, Avin A P and Prashanth P.

Effect of Fenugreek on Total Body and Organ Weights: A Study on Mice. Pharmacologyonline 2011;3:747-752.

80. Chevassus H, Gaillard JB, Farret A, Costa F, Gabillaud I, Mas E, et al. A fenugreek s e e d extract selectively reduces spontaneous fat intake in overweight subjects. Eur J C lin Pharmacol. 2010;66(5):449-455.

81. Geetha M, Suneel KR, Krupanidhi AM, Muralikrishna K S, Avin A P, Prashanth P. Effect of Fenugreek on Total Body and Organ Weights: A Study on Mice. Pharmacologyonline 3: 747-752 (2011).

82. Handa T, Yamaguchi $\mathrm{K}$, Sono $\mathrm{Y}$ and Yazawa $\mathrm{K}$. Effects of fenugreek seed extract in obese mice fed a high-fat diet. Biosci.Biotechbol.Biochem 2005; 69(6):1186-1188.

83. Kumar, P.; Bhandari, U.; Jamadagni, S. Fenugreek Seed Extract Inhibit Fat Accumulation and Ameliorates Dyslipidemia in High Fat Diet-induced Obese Rats. BioMed Res. Int. 2014, 2014, $1-11$.

84. Schroeter, H.; Boyd, C.; Spencer, J. P.; Williams, R. J.; Cadenas, E.; Rice-Evans, C. M A P K Signaling in Neurodegeneration: Influences of Flavonoids and of Nitric Oxide. N e u robiol. Aging. 2002, 23, 861-880.

85. Naidu, M. M.; Shyamala, B. N.; Naik, J. P.; Sulochanamma, G.; Srinivas, P. Chemical

Composition and Antioxidant Activity of the Husk and Endosperm of Fenugreek Seeds. LW T Food Sci. Tech. 2011, 44, 451-456. 
86. Mahabady, M. K.; Gholami, M. R.; Varzi, H. N.; Zendedel, A.; Doostizadeh, M. $\quad 2 \quad \begin{array}{llll}0 & 1 & 6\end{array}$. Protective Effect of Quercetin on Skeletal and Neural Tube Teratogenicity Induced by Cyclophosphamide in Rat Fetuses. Veterinary Research Forum, 7(2), 133-138.

87. Sharififar, F.; Khazaeli, P.; Alli, N. In Vivo Evaluation of Anti-inflammatory Activity of Topical Preparations from Fenugreek (Trigonella Foenum-graecum L.) Seeds in a Cream Base. Iran. J. Pharm. Sci. 2009, 5, 157-162.

88. Vijayakumar, M. V.; Bhat, M. K. Hypoglycemic Effect of a Novel Dialysed Fenugreek S e e d s Extract Is Sustainable and Is Mediated, in Part, by the Activation of Hepatic Enzymes. Phytother. Res. 2008, 22, 500-505.

89. Morcos SR, Elhawary Z, Gabrial GN. Protein-rich food mixtures for feeding the young in Egypt. 1. Formulation. Z Ernahrungs_wiss. 1981;20:275-282

90. Yoshikawa, T., Toyokuni, S., Yamamoto, Y., Naito, Y., 2000. Free radicals in chemistry biology and medicine. OICA International, London

91. Evans WC Trease and Evan's pharmacognosy, 13th edition. Balliere Tindall, London; 1991

92. Sharma RD, Sarkar A, Hazra DK, Misra B, Singh JB, Maheshwari BB (1996). Toxicological evaluation of fenugreek seeds: a long term feeding experiment in diabetic patients. Phytotherapy Research 10(6):519-520.

93. Howard M .Traditional folk remedies: A comprehensive herbal. Century Hutchinson Ltd., London; 1987 pp 134-138.
94. Moradi N, Moradi K .Physiological and pharmaceutical effects of fenugreek (Trigonella foenum-graecum L.) as a multipurpose and valuable medicinal plant. Global Journal of Medicinal Plant Research; 2013. 1(2):199-206.

95. Zandi P, Shirani Rad AH, Daneshian J, Bazrkar Khatibani L. Agronomic and morpho logic analysis of Fenugreek (Trigonella foenum-graecum L.) under nitrogen fertilizer and plant density via factor analysis. African Journal of Agricultural Research. 2011; 6(5): 1134-1140. DOI: 10.5897/AJAR11.004.

96. Bunney S. The illustrated book of herbs: their medicinal and culinary uses. Vol 1, No 2. London: Octopus Books; 1984. pp 320.

97. $\mathrm{Sh}$ a r m a R D, R a g h u ram T C, R a o VD .Hypolipidaemic effect of fenugreek seeds. A clinical study. Phytotherapy Research; 1991. 5(3):145- 147.

98. Doshi M, Mirza A, Umarji B, Karambelkar R, Effect of Trigonella foenum graecum (Fenugreek/ Methi) on Hemoglobin levels in females of Child Bearing Age, Biomedical Research, 23(1), 2001, 47- 50.

99. Kirtikar and Basu; "Indian Medicinal plants" International Book Distributors, 9/3, Rajpur Road (Ist floor) Dehradun-248001, India, Vol. I, Page. No.700-701.

100.Prajapati, Purohit, Sharma and Kumar; "A Handbook of Medicinal Plants- A Complete Source Book", Published by Agrobios (India), 2003, Page No.523. 